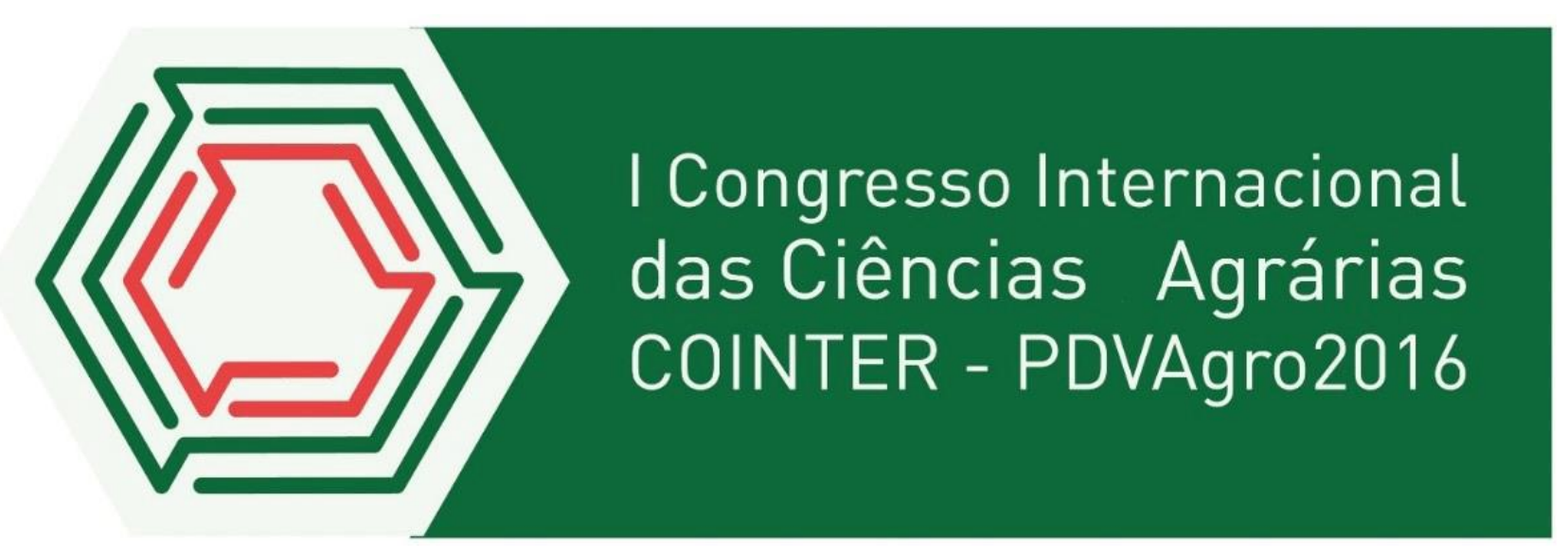

\title{
QUALIDADE DE ÁGUA: PRÁTICAS DESEMPENHADAS NO ESTÁGIO QUE SERIAM FUNDAMENTAIS PARA A SOCIEDADE; CADEIA PRODUTIVA OU PRODUTORES
}

Apresentação: Pôster

\begin{abstract}
Jeórgia Milena Alves Tavares ${ }^{1}$, Márcia Dantas dos Santos², Marino Eugênio de Almeida Neto $^{3}$
\end{abstract}

\section{Introdução}

A experiência do estágio é essencial para a formação integral do aluno, considerando que cada vez mais são requisitados profissionais com habilidades e bem preparados. Ao chegar à universidade o aluno se depara com o conhecimento teórico, porém muitas vezes, é difícil relacionar teoria e prática se o estudante não vivenciar momentos reais em que será preciso analisar o cotidiano (MAFUANI, 2011).

O estágio supervisionado vai muito além de um simples cumprimento de exigências acadêmicas, é uma oportunidade de crescimento pessoal e profissional. Além de ser um importante instrumento de integração entre universidade, escola e comunidade (FILHO, 2010).

O aprendizado é muito mais eficiente quando é obtido através da experiência; na prática o conhecimento é assimilado com muito mais eficácia, tanto é que se torna muito mais comum ao estagiário lembrar-se de atividades durante o percurso do seu estágio do que das atividades que realizou em sala de aula. Na efetiva prática de atividades supervisionadas o estagiário tem a possibilidade de entender vários conceitos que lhe foram ensinados na teoria. Por isso, o estudante deve perceber no estágio uma oportunidade única e realizá-lo com determinação, comprometimento

\footnotetext{
${ }^{1}$ Graduanda em Agroecologia pela Universidade Federal da Paraíba (UFPB), Campus-Bananeiras.

${ }^{2}$ Enfermeira. Mestranda pela Universidade pela Universidade Federal da Paraíba (UFPB), Campus-João pessoa.

${ }^{3}$ Biólogo. Doutor, Professor pela Universidade Federal da Paraíba (UFPB), Campus-Bananeiras.
} 
e responsabilidade. Seria apenas um desgaste caso não houvesse interesse em aprender e preparar-se para a futura profissão.

Neste sentido, o objetivo deste trabalho é apresentar a relação entre o estágio supervisionado e a disciplina de Sistema de Produção Agroecológica de Organismo Aquáticos.

\section{Fundamentação teórica}

A piscicultura é uma atividade que cresce a cada ano no Brasil. Essa prática tem como objetivo a criação de peixes, o que além de ser uma excelente fonte de renda para os criadores, é uma alternativa para a pesca comercial, pois, quando manejada adequadamente, não causa grandes impactos ambientais. A criação de peixes em cativeiro para o consumo e venda exige alguns cuidados, principalmente quanto a qualidade da água, que no caso da piscicultura, e o meio de cultivo no qual o animal está inserido. A utilização de rações, fertilizantes e as próprias excretas dos organismos mantidos nestes sistemas de produção deterioram a qualidade do ambiente de cultivo. Quando esses fatores estão associados a técnicas inadequadas de manejo e cultivo geram impactos e perturbações ambientais, causando impactos na saúde e sobrevivência dos peixes, além de danos aos ecossistemas adjacentes. Para evitar isso, é importante que o piscicultor saiba cuidar da água dos tanques de criação para que o peixe alcance um bom índice de crescimento, ganhando peso e reduzindo o tempo de cultivo e o efluente de seu cultivo não cause problemas ambientais. $\mathrm{O}$ monitoramento constante é fundamental para garantir que os peixes tenham uma água de boa qualidade em seu ambiente de cultivo. Com isso, a atividade obterá ganhos de produtividade mantendo a qualidade dos ecossistemas adjacentes.

É fundamental que o profissional responsável conheça as características físicas, químicas e biológicas da água. Em sistemas de cultivo de peixes, os principais parâmetros da água a serem monitorados são: temperatura, oxigênio dissolvido (OD), pH, $\mathrm{CO}_{2}$, alcalinidade, dureza, transparência, nutrientes e quantidade de plâncton (PÁDUA, 2001); A temperatura é um parâmetro físico de grande importância, pois afeta o desenvolvimento dos organismos aquáticos (SIPAÚBATAVARES, 1995; KUBITZA, 2003) e exerce influência sobre outros parâmetros da água (SIPAÚBATAVARES, 1995; VINATEA-ARANA, 2004).

O OD é o parâmetro químico mais importante para os organismos aquáticos (SIPAÚBATAVARES, 1995.; KUBITZA, 2003). Quando em baixa concentração, pode atrasar o crescimento, 
reduzir a eficiência alimentar e aumentar a incidência de doenças e de morte (KUBITZA, 2003). A concentração de OD varia, ao longo do dia, em função da fotossíntese e da respiração. Logo, quanto maior a quantidade de organismos por unidade de volume, maior a variação diária na concentração desse gás (ESTEVES, 1998; KUBITZA, 2003; VINATEA - ARANA, 2004).

$\mathrm{O}$ pH, por sua vez, sofre uma variação ao longo do dia, em função da fotossíntese e da respiração, diminuindo com o aumento da concentração de $\mathrm{CO} 2$ na água. Águas com pouco OD apresentam grande concentração de $\mathrm{CO} 2$ e pH baixo. Valores de pH abaixo de 6,0 e acima de 9,5 atrapalham o crescimento e a reprodução dos organismos aquáticos (KUBITZA, 2003),

A transparência indica a penetração vertical da luz solar na coluna d’água em viveiros. Essa está intimamente relacionada com a presença de plâncton ou de solo em suspensão. Águas com elevado grau de transparência contribuem para o crescimento de algas e plantas. No entanto, essas podem prejudicar a disponibilidade oxigênio no mesmo, que também pode ser insuficiente diante de uma baixa transparência (EMBRAPA, 2013).

A piscicultura requer conhecimentos específicos para garantir sua manutenção e produtividade. Cuidados com fatores que interferem diretamente na qualidade da água e saúde dos peixes como os supracitados, são de fácil monitoramento e responsabilidade do produtor.

\section{Metodologia}

O estágio supervisionado foi realizado no Laboratório de Aquicultura do Colégio Agrícola "Vidal de Negreiros" (CAVN), Centro de Ciências Humanas, Sociais e Agrárias (CCHSA), Universidade Federal da Paraíba (UFPB), no município de Bananeiras - PB do período de 08 de fevereiro à 07 junho de 2016. O laboratório de aquicultura dispõe de uma área de 11 hectares, com aproximadamente 33 viveiros. Sendo divididos em três áreas: sendo a primeira destinada para reprodução, com viveiros de descanso, acasalamento e indução sexual. A segunda engloba pavilhão de incubação de pós-larva e área de engorda, com viveiros de recria e engorda. E por fim, o galpão de ração.

As atividades realizadas durante o estágio supervisionado seguia em analisar alguns parâmetros físicos de 2 viveiros escavados em atividade. Esse possuía uma área de $1000 \mathrm{~m}^{2}$; com um sistema de policultivo, onde eram criados camarões (Macrobrachium rosembergii) e peixes (Oreocromis niloticus) com uma densidade de estocagem de 20 animais por $\mathrm{m}^{2}$ e 2 animais por $\mathrm{m}^{2}$, 
respectivamente. Pela manhã era realizado as leituras de $\mathrm{pH}$, oxigênio dissolvido e temperatura às 06:00 e 07h:00 da manhã e a tarde entre 16:30 e 17:00h. Quanto a transparência da água se fazia às 12h:00 no mesmo ponto. Esses parâmetros eram mensurados diariamente durante cinco meses e duas vezes na semana eram feitas limpeza nos viveiros, para retirar as macrofitas.

\section{Resultados e Discussões}

Durante o período do estágio observou-se alguns parâmetros fundamentais para um cultivo de organismos aquáticos. Estes se mostraram regulares, diante dos valores ideais. Monitoramento, medição ou verificação de parâmetros de qualidade e quantidade de água, que pode ser contínua ou periódica, utilizada para acompanhamento da condição e controle da qualidade do corpo de água (CONAMA, 2005). Os registrados mensurados foram de: temperatura, $\mathrm{pH}$, oxigênio dissolvido, temperatura e transparência.

A Temperatura observada foi de $26^{\circ} \mathrm{C}$ pela manhã e $27^{\circ} \mathrm{C}$ pela tarde, em condições climáticas habituais. Tendo uma variação de queda de $-1{ }^{\circ} \mathrm{C}$ em tempos chuvosos, com $25^{\circ} \mathrm{C}$ pela manhã e $26^{\circ} \mathrm{C}$ durante à tarde, em comparação com os valores supracitados. Esses parâmetros estão entre os valores aceitáveis conforme menciona Rocha e Paulino (2007), que para a piscicultura tropical a faixa ideal para o cultivo está entre $26^{\circ} \mathrm{C}$ e $30^{\circ} \mathrm{C}$. Controlar a temperatura da água dos viveiros é algo um tanto difícil, uma vez que, estes estão ao céu aberto, expostos às variações climáticas. (OSTRENSKY; BOEGER, 1998). A temperatura é um parâmetro que tem influência sobre o crescimento, uma vez que, níveis mais elevados estimulam a atividade metabólica, requerendo maior necessidade de consumo de alimento e, consequentemente, o crescimento (KUBITZA, 1998).

Os níveis de oxigênio dissolvido observados foram de $4 \mathrm{mg} / \mathrm{L}$. Esse valor Esse deve ser monitorados diariamente em cada viveiro ou tanque de produção. Níveis máximos e mínimos de oxigênio dissolvido normalmente ocorrem, respectivamente, ao final da tarde e ao amanhecer em viveiros de baixa renovação de água. O monitoramento diário deste valore ajudam a prever a ocorrência de níveis críticos de oxigênio dissolvido, possibilitando a aplicação de aeração de emergência. Baixa concentração de Oxigênio dissolvido causa atraso ao crescimento do organismo cultivado, redução na eficiência alimentar dos peixes, aumento na incidência de doenças e na mortalidade dos peixes, resultando em sensível redução na produtividade. Há métodos, dos quais, os produtores podem utilizar para manter o OD no recomendado. Estes são: renovação da água dos 
viveiros, uso de equipamentos específicos como aeradores e sempre manter a níveis recomendados os parâmetros de $\mathrm{pH}$, temperatura e transparência, dentre outros (EMBRAPA, 2000).

$\mathrm{O}$ pH, por sua vez, variou de valores de 6,6 e 7,0. Esse deve ser monitorados diariamente em cada viveiro ou tanque de produção, pois é um parâmetro que está relacionado com a concentração de íons $\mathrm{H}^{+}$na água. Por isso é de suma importância manter na faixa ideal o $\mathrm{pH}$ pois afeta o metabolismo de várias espécies aquáticas. A Resolução CONAMA 357 estabelece que para a proteção da vida aquática o $\mathrm{pH}$ deve estar entre 6 e 9. Alterações nos valores de $\mathrm{pH}$ também podem aumentar o efeito de substâncias químicas que são tóxicas para os organismos aquáticos.

Quanto à transparência os valores excederam a faixa de normalidade com 60 e $70 \mathrm{~cm}$. Diante disso, foi realizado uma correção com cal virgem numa dose $50 \mathrm{~kg} / 1.000 \mathrm{~m}^{2}$. Quando a água está transparente, pobre em plâncton, além dos problemas relacionados ao pouco crescimento dos peixes, nos deparamos com o crescimento de vegetações indesejáveis (flutuantes, submersas ou emergentes) dentro dos viveiros, favorecido pela penetração mais intensa dos raios solares nas águas mais "cristalinas". Essas vegetações, (macrofitas) prejudicam as despescas se prendendo e danificando as redes, a água muito transparente, facilita os predadores a atuarem, já que visualizam melhor os peixes. A faixa ideal de transparência para cultivos de alguns organismos aquáticos está entre 30 e $40 \mathrm{~cm}$. Quando a transparência for maior que $40 \mathrm{~cm}$, significa que a água está pobre em plâncton e precisa ser adubada, assim como a renovação da água interrompida. Quando for menor que $30 \mathrm{~cm}$, significa excesso de plâncton, devendo ser interrompida (KUBITZA, 1998).

\section{Conclusões}

Inserir o aluno no contexto do mercado de trabalho para conhecimento da realidade onde possibilitar o confronto entre o conhecimento teórico e a prática adotada; Agregar valores junto ao processo de avaliação institucional, a partir do resultado do desempenho do aluno no mercado de trabalho.

\section{Referências}

GUBA, E. G.; LINCOLN, Y. S. Fourth generation evaluation. Newbury Park, London, New Delhi: Sage, 1989.

HOFFMAN, J. Avaliação mediadora: uma prática em construção da pré-escola à universidade. 
Porto Alegre: Mediação, 2001.

LIMA, K. S. Compreendendo as concepções de avaliação de professores de física através da teoria dos construtos pessoais. Recife, 2008. 163 p. Dissertação (Ensino das Ciências). Departamento de Educação, UFRPE, 2008.

SALES, E. S.; MONTEIRO, I. G. S.; LIMA, K. S. Formação de professor, diretrizes da Educação brasileira para o ensino de Química e Avaliação: saberes docentes essenciais à formação docente. In: VII Colóquio Internacional Educação e Contemporaneidade, 2013, São Cristóvão - SE. Anais do Colóquio Internacional Educação e Contemporaneidade, 2013.

NARDI, R.; CORTELLA, B. S. C. Formação de professores de Física: das intenções legais ao discurso dos formadores. In: XVI Simpósio Nacional de Ensino de Física, 2005, Rio de Janeiro. Caderno de Resumos. São Paulo - SP: Sociedade Brasileira de Física, 2005. v. 1. p. 175-175, 2005.

EMBRAPA. Parâmetros ambientais e qualidade da agua na piscicultura 2000.

EMBRAPA. Pesca e Aquiqultura. QUALIDADE DA AGUA: Piscicultura Familiar 2013. 